\title{
A Genre and Collocational Analysis of Consequence, Result, and Outcome
}

\author{
SUPAKORN PHOOCHAROENSIL \\ Language Institute of Thammasat University, Thailand \\ supakorn.p@litu.tu.ac.th
}

\begin{abstract}
This corpus-based study examines genres and collocation patterns in which the three synonyms 'consequence', 'result', and 'outcome' usually occur. The data on which the study is based is derived from the Corpus of Contemporary American English (COCA). Of all the eight genres currently available in COCA, the three synonyms appear with the highest frequency in academic texts, whereas frequencies are lowest in informal genres, i.e. TV and movie subtitles and fiction. Of pedagogical concern is the fact that the common verb and adjective collocates repeatedly co-occur with the synonymous nouns. Determined by the COCA frequency and the MI value ( $\geq 3)$, 'consequence' is often used with verbs and adjectives conveying negative senses, and the typical collocates of 'result' has a clear association with research-oriented contexts. The collocates of 'outcome' have the broadest variety of semantic properties but are not directly related to any specific contexts. It is highly recommended that EFL teachers apply this genre and collocational information to synonym development lessons.
\end{abstract}

Keywords: synonym; genre; distribution across genres; collocation; adjective and verb collocates

\section{INTRODUCTION}

Vocabulary learning is a key to second language (L2) acquisition. Out of all lexical items, synonyms often prove to be challenging for learners' acquisition of L2 vocabulary (Sridhanyarat, 2018). According to Webb and Nation (2017), a synonym refers to "a word or phrase that has the same meaning as another word or phrase" (p. 284). Theoretically speaking, synonymy is a bilateral or symmetrical lexical relation in which two or more linguistic forms share the same meaning (Szudarski, 2018). Semanticists investigate synonymy by looking at a relationship of similarity or sameness of meaning between two or more words (Jackson and Amvela, 2007). A more layperson's definition of synonym is provided in the Cambridge Advanced Learner's Dictionary (2013), in which it is defined as "a word or phrase that has the same or nearly the same meaning as another word or phrase in the same language", with small and little being examples of synonymous words (p. 1596). As a matter of fact, no nearsynonyms are identical in every detail, and replacing one with its synonym can lead to some deviation or ungrammaticality in L2 (Thornbury, 2002).

The synonyms being investigated in this study are the nouns consequence, result, and outcome. The three words could cause confusion for many EFL students and teachers since they are very close in meaning. Those whose L2 English exposure is limited may treat nearsynonyms like the target ones as interchangeable in different contexts, resulting in a less natural L2 use (Szudarski, 2018).

The definitions of the three target synonyms from three American-English dictionaries, namely Longman Advanced American Dictionary (2013), Oxford Advanced American Dictionary (online version), and Merriam-Webster Dictionary (online version), are shown in Table 1:

TABLE 1. Definitions and examples of consequence, result, and outcome from American-English dictionaries

\begin{tabular}{lccc}
\hline & $\begin{array}{c}\text { Longman Advanced American } \\
\text { Dictionary }\end{array}$ & $\begin{array}{c}\text { Oxford Advanced } \\
\text { American Dictionary }\end{array}$ & $\begin{array}{c}\text { Merriam-Webster } \\
\text { Dictionary }\end{array}$ \\
\hline 1. consequence & $\begin{array}{c}\text { something that happens as a result of a } \\
\text { particular action or situation (p. 358) }\end{array}$ & $\begin{array}{c}\text { a result of something that } \\
\text { has happened }\end{array}$ & $\begin{array}{c}\text { something produced by a } \\
\text { cause or necessarily } \\
\text { following from a set of } \\
\text { conditions }\end{array}$ \\
\hline
\end{tabular}




\begin{tabular}{|c|c|c|c|}
\hline & $\begin{array}{l}\text { e.g. Ignoring safety procedures can } \\
\text { have potentially tragic consequences. }\end{array}$ & $\begin{array}{l}\text { e.g. This decision could have } \\
\text { serious consequences for } \\
\text { the industry. }\end{array}$ & $\begin{array}{l}\text { e.g. The slightest error can } \\
\text { have serious consequences. }\end{array}$ \\
\hline \multirow[t]{2}{*}{ 2. result } & $\begin{array}{l}\text { something that happens or exists } \\
\text { because of something that happened } \\
\text { before (p. 1458) }\end{array}$ & $\begin{array}{l}\text { a thing that is caused or } \\
\text { produced because of } \\
\text { something else }\end{array}$ & $\begin{array}{l}\text { something that results as a } \\
\text { consequence, issue, or } \\
\text { conclusion }\end{array}$ \\
\hline & $\begin{array}{l}\text { e.g. Her cough is the result of years of } \\
\text { smoking. }\end{array}$ & $\begin{array}{l}\text { e.g. The failure of the } \\
\text { company was a direct result } \\
\text { of bad management. }\end{array}$ & $\begin{array}{l}\text { e.g. The book is the result of } \\
\text { years of hard work and } \\
\text { dedication. }\end{array}$ \\
\hline \multirow[t]{3}{*}{ 3. outcome } & $\begin{array}{l}\text { the final result of a meeting, process, } \\
\text { series of events, etc., especially when } \\
\text { no one knows what it will be until it }\end{array}$ & $\begin{array}{l}\text { the final result of an action } \\
\text { or event }\end{array}$ & $\begin{array}{l}\text { something that follows as a } \\
\text { result or consequence }\end{array}$ \\
\hline & actually happens (p. 1211) & $\begin{array}{l}\text { e.g. We are waiting to hear } \\
\text { the outcome of the }\end{array}$ & $\begin{array}{l}\text { e.g. We are still awaiting the } \\
\text { final outcome of the trial. }\end{array}$ \\
\hline & $\begin{array}{l}\text { e.g. Both sides are hoping for a } \\
\text { positive outcome. }\end{array}$ & negotiations. & \\
\hline
\end{tabular}

It is quite clear from the above definitions that consequence, result, and outcome are similar in meaning and thus are considered near-synonyms of one another. Some information about their usage, e.g. formality, collocations, is available but not comprehensive.

With regard to formality, outcome and consequence are considered formal as they are both listed in the Academic Word List or AWL (Coxhead, 2000). However, the degree of formality of result is not clearly determined in the dictionaries being consulted. In terms of collocations, a list of adjective collocates of result is available in Longman Advanced American Dictionary, i.e. catastrophic, desired, direct, disastrous, end, final, good, inevitable, mixed, net, immediate, and positive, and that of verb collocates, i.e. achieve, have, obtain, produce, and yield, are available in Longman Advanced American Dictionary. However, no adjective collocational information is provided for consequence and outcome in any one of the three dictionaries.

Such limitations of the dictionary information may be a reason why English learners sometimes find it difficult to make a clear distinction among near-synonyms so that they can use them in appropriate contexts (e.g. Lee and Liu, 2009; Ly and Jung, 2015). This provided the motivation for this corpus-based synonym study. In the next section, two major kinds of synonyms, ways to distinguish synonyms, and some past corpus-based studies on synonyms are reviewed.

\section{LITERATURE REVIEW}

\section{PERFECT SYNONYMS VS. NEAR-SYNONYMS}

Two major types of synonyms commonly known in lexicology are 'perfect synonyms' and 'near-synonyms'. Perfect synonyms, also known as absolute synonyms, refer to a pair of synonyms in which all meanings of both words are identical and they can be used interchangeably in all contexts (Taylor, 2002). By this definition, such perfect synonyms are extremely rare, if not non-existent as it is uneconomical for a language to have two words the meanings of which are truly identical. By contrast, near-synonyms or loose synonyms are defined as vocabulary items whose senses are identical in respect of central semantic traits, but differ in minor or peripheral traits (Cruse, 1986). In other words, near-synonyms share some core or central meanings but differ in some respects. They are therefore not interchangeable in all contexts. As can be seen in the example sentences below, it is acceptable to use the pair of 
near-synonyms repair and mend interchangeably in (1), but mend rather than repair sounds more natural in (2), where the context is clothes.

(1) I will mend/repair that light in the hall.

(2) My father used to mend/*repair his shoes.

\section{DISTINGUISHING SYNONYMS}

Near-synonyms can be differentiated using a number of criteria, e.g. formality of the context and collocation and semantic prosody (Jackson and Amvela, 2007).

DEGREE OF FORMALITY

To distinguish synonyms in English, it is also possible to investigate the words in terms of formality or style. Although a pair of words is very similar in meaning, one may be more preferable in a more formal context, while the other tends to occur in a less formal context. A clear example of this is the synonyms plead, appeal and ask. As noted in Phoocharoensil (2010)'s study, ask is more common in an informal style, whereas plead and appeal are often associated with a higher degree of formality.

Some additional examples of English words differing in the degree of formality are provided below:

\author{
Formal \\ refuse \\ receptacle \\ obtain
}

\author{
Informal \\ rubbish \\ bin \\ get
}

(Longman advanced American dictionary, 2013)

\section{COLLOCATIONS AND SEMANTIC PROSODIES}

Another very useful way to differentiate synonyms is by looking at their possible collocates, i.e. frequently co-occurring word or phrases, and semantic prosodies. The concept of collocation refers to relations between words whose probability of occurrence can be objectively measured. The meaning of a word is dependent on not merely what it possesses in itself but also on how it combines with other neighboring words (Flowerdew, 2012). In brief, collocations are words that commonly occur together (Webb and Nation, 2017, p. 276).

It is of crucial importance to note that synonymous words are sometimes different when collocated with the word partners in which they usually co-occur. Despite the fact that shake and wag both describe the action of moving suddenly from side to side, it is clear that wag strongly collocates with the subject noun $d o g$, while shake tends to have a wider range of noun collocates, such as hand, head, body, bottle, etc.

In addition, closely connected with the concept of collocation is semantic prosody, defined as "a consistent aura of meaning with which a form is imbued by its collocates" (Louw, 1993, p. 157). Semantic prosody deals with evaluative or attitudinal meanings resulting from a word's co-occurrence with specific collocations. Nowadays corpus-based techniques largely contribute to studies in semantic prosody since it can be observed with higher degrees of accuracy by looking at co-occurring words or phrases (Flowerdew, 2012; Szudarski, 2018).

One of the classic corpus-based studies examining semantic prosodies is Stubbs (1995), in which the analysis of the verbs cause was the focus. Stubbs discovered certain significant differences in the collocational patterns of both verbs. To be more specific, cause often collocates with negative words, e.g. accident, alarm, concern, confusion, damage, death, delay, 
fire, harm, trouble, whereas the common collocates of its synonym bring about are often positive, e.g. job, growth, progress, revival, joy, happiness, and sometimes negative, e.g. collapse, recession, disaster, as shown in the Corpus of Contemporary American English (COCA).

In summary, collocations play a vital role in language use. As Thornbury (2002) maintained, "Even the slightest adjustments to the collocation - by substituting one of its components for a near-synonym...turns the text into non-standard English" (p. 7). It is an undeniable linguistic fact that collocation "provides the key to native-like fluency and ease of production" (Barnbrook, Mason, and Krishnamurthy, 2013, p. 129).

\section{PREVIOUS STUDIES ON SYNONYMS}

A number of researchers have conducted studies on synonyms with an emphasis on their similarities and differences. Corpus-based lexical studies in this area were conducted as they are far more reliable than traditional descriptive research (Chung, 2011).

First, Phoocharoensil (2010) analysed five synonyms, namely ask, beg, plead, request, and appeal, with the purpose of comparing the information from three learner dictionaries, i.e. The Oxford Advanced Learner's Dictionary, The Longman Dictionary of Contemporary English, and The Cambridge Advanced Learner's Dictionary, and that drawn from a corpus of Time in 1995. The study revealed that although some principal meanings of these synonyms overlap, they also differ in several aspects, such as subtle meanings, collocations, degree of formality, and grammatical patterns. Interestingly, the findings indicated that ask and beg occur in less formal contexts than plead, request, and appeal. The target synonyms have not only similar but also different collocations and grammatical patterns. It is noteworthy that the researcher discovered additional grammatical patterns that are not presented in dictionaries.

Chung (2011) carried out a corpus-based study on two synonyms, create and produce with a focus on verb form and meaning, using data from the Brown Corpus and the FreiburgBrown (Frown) Corpus. Having compared the data from the two aforementioned corpora with the British National Corpus (BNC), Chung reported two overlapping meanings of both verbs, i.e. 'bring into existence/cause to happen, occur, or exist' and 'create or manufacture a manmade product'. Furthermore, it was indicated that the objects following produce are naturally mixed, e.g. crops, goods, as it normally refers to factory-made products. In contrast, create allows more creativity since it is often followed by an object whose properties are not fixed, e.g. problems, image.

Apart from the BNC, several recent studies are based on language data from a very large corpus like the Corpus of Contemporary American English (COCA), focusing on different linguistic aspects, e.g. collocations, formality, distribution across text types (e.g. Crawford and Csomay, 2016; Jirananthiporn, 2018; Petcharat and Phoocharoensil, 2017) without referring to any statistics to confirm statistically significant level of collocational strength, with the exception of Aroonmanakun's (2015) study.

Among the studies using data from COCA, Crawford and Csomay (2016) explored two synonyms, i.e. equal and identical, in COCA. Although the two words are interchangeable in certain contexts, such as These two students are equal/identical in the performance on the exam. (p. 6), some differences in collocations with which they occur can be witnessed through corpus-based information. In looking at both synonyms with corpus evidence, they pointed out the benefits of language corpora in facilitating their observation, which are beyond native speakers' intuition. They discovered that equal is more likely to co-occur with abstract concepts, e.g. opportunities, rights, and protection, whereas identical is frequently combined with concrete nouns, e.g. twins, houses, and items. Furthermore, in terms of frequency, occurrences of equal (20,480 times) outnumber those of identical (8,080 times). Crawford and 
Csomay highlight the importance of accessible reference to large amounts of texts included in corpora, which enhances their linguistic analysis.

In a corpus-based study by Petcharat and Phoocharoensil (2017), three synonyms, appropriate, proper, and suitable were examined based on the information from COCA in comparison with three learner dictionaries. It was shown that the three target synonyms, though sharing some core meanings, have usage differences in some respects. In particular, appropriate is at the highest level of formality, followed by suitable and proper respectively. In terms of collocations, they all share one noun collocate, i.e. place, and proper has the highest number of noun collocates probably because it covers more senses of meaning than appropriate and suitable. In addition, the grammatical patterns in which appropriate and suitable occur outnumber those in which proper does. It was concluded that corpus data highlights the differences between these synonyms in formality, collocations, and grammatical patterns.

Another insightful study by Jirananthiporn (2018) analysed corpus-based data of the synonyms problem and trouble, two nouns that often pose problems for EFL learners. The data from COCA demonstrates the distribution patterns of both words across five text types: spoken, fiction, magazine, newspaper, and academic. Problem occurs with far higher frequency than trouble in all the text types. In addition, trouble is more common in spoken texts than in formal written genres. This has been supported by the verb collocates of problem, most of which are characteristic of written discourse, e.g. alleviate, eliminate, rectify, acknowledge, analyze, identify, address, confront, exacerbate. However, the verb collocates of trouble have a lower level of formality, e.g. ask, expect, like, mean, invite, want, spell, start, and give.

Different from the previously cited studies which involved no inferential statistics in collocation analysis, Aroonmanakun (2015) explored the similarities and differences of the synonymous adjectives quick and fast in COCA, extracting the top 100 collocates of both synonyms with MI scores of at least 3 . The results revealed that the two synonyms have different noun collocates. For example, quick collocates with answer, breakfast, comment, reaction, reference, solution, tip, visit, most of which refer to the action having been done or responded to in a short time. The common noun collocates of fast, in contrast, indicate the manner of movement rather than a short period of time, e.g. acceleration, attack, boat, car, ride, tempo. While quick and fast can sometimes modify the same noun, e.g. learner, the meaning of the noun combined with each individual adjective is different. More precisely, $a$ fast learner learns some skills in a short time, whereas a quick learner is able to learn something in an easy manner. Aroonmanakun found support for Phoocharoensil (2010) and Petcharat and Phoocharoensil (2017) in that information on collocations from language corpora outweighs that existing in learner dictionaries.

The advent of the latest version of COCA, consisting of three new genres, namely TV and Movie subtitles, blogs, and webpages (Davies, 2020), and the collocation analysis based on the MI scores were the motivation for the present study on the similarities and differences between the synonymous nouns consequence, result, and outcome with an emphasis on distribution across eight genres and collocations. The present study thus aims to investigate the three target synonyms in response to the research questions below:

1. How are the synonyms consequence, result, and outcome distributed across different genres? 2. What are the common collocations of the synonyms consequence, result, and outcome?

\section{METHODOLOGY}

\section{DATA COLLECTION}

The data of the present study was drawn from the Corpus of Contemporary American English (COCA), a very large, genre-balanced corpus of American English. COCA is probably the 
most widely-used corpus of English for ELT research and practice, and it contains more than one billion words of text, approximately 20 million words being included each year from 19902019. Nowadays COCA encompasses texts of eight different genres, namely five conventional genres, i.e. spoken, fiction, popular magazine, newspaper, and academic texts, and three new genres, i.e. TV and Movie subtitles, blogs, and webpages.

COCA is a very useful corpus resource for a number of reasons (Schmitt, 2010). First, with its enormous size, COCA represents American English and is vastly larger than any other available American English corpus (Davies, 2020). It is also considered a counterpart to the British National Corpus (BNC), which was originally created by Oxford University Press in the 1980s and early 1990s and contains 100 million words of texts from a wide range of genres, such as spoken, fiction, magazine, newspaper, and academic. Second, COCA comprises data based on texts being equally divided among different genres. Such an equal division explains why COCA is one of the biggest and well-developed corpora of present-day English (Davies, 2020). The third reason lies in the fact that COCA is not a static but a 'monitor' corpus, meaning that new texts are continuously added to the corpus, thereby annually increasing its size.

The current study aimed to answer the two research questions. COCA was first consulted for frequencies and distribution across genres of the target synonyms, i.e. consequence, result, and outcome, in all of the eight different genres. In responding to the second research question, the researcher searched for verb and adjective collocates frequently accompanying the three synonymous nouns. The typical collocates were selected based on the collocational strength measured by statistical corpus-based methods (Wongkhan and Thienthong, 2020). The corpus statistics used to identify collocations for this study is the Mutual Information (MI) value or score, which determines whether two words co-occur by chance or have a strong association in terms of collocation. However, the MI value is not without limitations. It is likely that rare occurrences will achieve prominence in the MI list (Cheng, 2012). In other words, some collocations with high MI scores may not be the most representative examples since the number of occurrences in a corpus can be very low (Szudarski, 2018). As Schmitt (2010) pointed out, it is necessary that the MI score be used in conjunction with a minimum frequency threshold. Thus, in this study, the strength of collocation was measured by a combination of both frequency and the MI value. The verb collocates that are in the top-20 frequency list presented in COCA and whose MI score is $\geq 3$, which is the significance value for collocational association, were chosen (Cheng, 2012). For adjective collocate selection, the same criteria were applied but the range was expanded to cover adjectives in the top-30 frequency list due to their higher frequency in COCA, compared to that of verb collocates.

\section{RESULTS AND DISCUSSION}

In response to the two research questions, the findings as regards the overall frequency of the three target synonyms in eight different genres are presented first, followed by the collocations with which the synonyms are commonly used.

FREQUENCY AND DISTRIBUTION OF ACROSS GENRES

TABLE 2. Overall frequency and distribution of consequence, result, and outcome across eight genres

\begin{tabular}{|c|c|c|c|c|c|c|c|}
\hline \multirow[b]{2}{*}{ Genre } & \multicolumn{2}{|c|}{ consequence } & \multicolumn{2}{|c|}{ result } & \multicolumn{2}{|c|}{ outcome } & \multirow{3}{*}{$\begin{array}{c}\text { Total } \\
\text { frequency }\end{array}$} \\
\hline & Frequency & $\begin{array}{c}\text { Per } \\
\text { million }\end{array}$ & Frequency & $\begin{array}{c}\text { Per } \\
\text { million }\end{array}$ & Frequency & $\begin{array}{c}\text { Per } \\
\text { million }\end{array}$ & \\
\hline spoken & 1,134 & 8.99 & 8,197 & 64.99 & 3,196 & 25.34 & \\
\hline
\end{tabular}




\begin{tabular}{|c|c|c|c|c|c|c|c|}
\hline fiction & 759 & 6.41 & 2,545 & 21.51 & 811 & 6.85 & \\
\hline magazine & 1,635 & 12.97 & 18,342 & 145.47 & 2,763 & 21.91 & \\
\hline newspaper & 778 & 6.39 & 14,629 & 120.16 & 2,881 & 23.66 & \\
\hline $\begin{array}{l}\text { academic } \\
\text { texts }\end{array}$ & 4,844 & 40.44 & 66,534 & 555.42 & 11,921 & 99.52 & \\
\hline $\begin{array}{c}\text { TV and } \\
\text { movies } \\
\text { subtitles }\end{array}$ & 370 & 2.89 & 3,768 & 29.42 & 665 & 5.19 & \\
\hline blogs & 2,029 & 15.78 & 19,371 & 150.61 & 5,130 & 39.89 & \\
\hline webpages & 2,728 & 21.96 & 22,417 & 180.41 & 5,062 & 40.74 & \\
\hline Total & 14,277 & & 155,803 & & 32,429 & & 202,509 \\
\hline
\end{tabular}

Table 2 clearly shows that of all the three synonyms, result occurs with the greatest frequency. More specifically, the number of occurrences of result (155,803 tokens) is over five times higher than that of outcome (32,429 tokens), while consequence is the least frequent $(14,277$ tokens).

As can be seen in Table 3, the three synonyms all have a very high degree of formality, as their occurrences are highest in number in academic texts, with result being the most frequent $(66,534$ tokens), followed by outcome (11,921 tokens) and consequence $(4,844$ tokens), respectively. This observation is borne out by the lowest frequency of the three synonyms in informal contexts. In particular, result occurs with the lowest frequency in fiction (2,545 tokens), TV and movie subtitles (3,768 tokens), and spoken (8,197 tokens) respectively, all of which are representative of informal or colloquial English. In a similar vein, the frequency of outcome is lowest in TV and movie subtitles (665 tokens) and fiction (811 tokens), respectively. Like the distribution of outcome, consequence has the lowest frequency in TV and movie subtitles (370 tokens), followed by fiction (759 tokens) and newspapers (778 tokens), respectively.

TABLE 3. Distribution of consequence, result, and outcome across eight genres according to frequency

\begin{tabular}{|c|c|c|c|c|c|c|c|c|}
\hline \multirow[b]{2}{*}{ Genre } & \multicolumn{2}{|c|}{ consequence } & \multicolumn{4}{|c|}{ result } & \multicolumn{2}{|c|}{ outcome } \\
\hline & Frequency & $\begin{array}{c}\text { Per } \\
\text { million }\end{array}$ & Genre & Frequency & $\begin{array}{c}\text { Per } \\
\text { million }\end{array}$ & Genre & Frequency & $\begin{array}{c}\text { Per } \\
\text { million }\end{array}$ \\
\hline $\begin{array}{l}\text { academic } \\
\text { texts }\end{array}$ & 4,844 & 40.44 & $\begin{array}{l}\text { academic } \\
\text { texts }\end{array}$ & 66,534 & 555.42 & $\begin{array}{c}\text { academic } \\
\text { texts }\end{array}$ & 11,921 & 99.52 \\
\hline webpages & 2,728 & 21.96 & webpages & 22,417 & 180.41 & blogs & 5,130 & 39.89 \\
\hline blogs & 2,029 & 15.78 & blogs & 19,371 & 150.61 & webpages & 5,062 & 40.74 \\
\hline magazine & 1,635 & 12.97 & magazine & 18,342 & 145.47 & spoken & 3,196 & 25.34 \\
\hline spoken & 1,134 & 8.99 & newspaper & 14,629 & 120.16 & newspaper & 2,881 & 23.66 \\
\hline newspaper & 778 & 6.39 & spoken & 8,197 & 64.99 & magazine & 2,763 & 21.91 \\
\hline fiction & 759 & 6.41 & $\begin{array}{l}\text { TV and } \\
\text { movies } \\
\text { subtitles }\end{array}$ & 3,768 & 29.42 & fiction & 811 & 6.85 \\
\hline $\begin{array}{c}\text { TV and } \\
\text { movies } \\
\text { subtitles }\end{array}$ & 370 & 2.89 & fiction & 2,545 & 21.51 & $\begin{array}{c}\text { TV and } \\
\text { movies } \\
\text { subtitles }\end{array}$ & 665 & 5.19 \\
\hline Total & 14,277 & & & 155,803 & & & 27,333 & \\
\hline
\end{tabular}

In addition, all three synonyms occur frequently in webpages and blogs, i.e. two similar text types which are considered new genres of COCA (Davies, 2020). Due to the high level of formality of the nouns consequence, result, and outcome, it is assumed that the two newly added genres, webpages and blogs, belong to formal text types but following academic texts in their degree of formality.

The next section pertains to the common verb and adjective collocates of the nouns consequence, result, and outcome, corresponding to the second research question. 


\section{COMMON COLLOCATIONAL PATTERNS}

\section{VERB COLLOCATES}

In this section, verb collocates that are frequently used with the nouns consequence, result, and outcome are shown and discussed. The selected verbs have at least $\geq 3$ of the MI value to confirm their statistical significance (Cheng, 2012; Schmitt, 2010).

From Table 4, there exist only 15 frequent verb collocates of consequence and 17 of result based on frequency and MI scores $(\geq 3)$, while more than 20 verbs can frequently collocate with outcome. Therefore, only the top- 20 verb collocates are presented in the table. Surprisingly, some of the target synonymous nouns share common collocates. In particular, consequence and outcome strongly collocate with the verb anticipate, while outcome and results share some verb collocates, e.g. achieve, yield. Nevertheless, the existence of shared collocates in Table 4 should be interpreted with some caution. Some verbs, e.g. show, can actually co-occur with all the three target synonyms but are not included due to either its low frequency or low MI value in COCA. Moreover, some other verbs that are frequent in English and can co-occur with all the three target nouns are not existent in the corpus probably because they constitute weak collocations, such as the verb have, which can collocate with a multitude of neighboring words, e.g. have + consequence/ result/ outcome (Hill, 2000).

TABLE 4. Verbs collocates of consequence, result, and outcome in COCA

\begin{tabular}{|c|c|c|c|c|c|c|c|c|c|}
\hline \multirow[t]{2}{*}{ Rank } & \multicolumn{3}{|c|}{ consequence } & \multicolumn{3}{|c|}{ result } & \multicolumn{3}{|c|}{ outcome } \\
\hline & $\begin{array}{c}\text { Verb } \\
\text { collocate }\end{array}$ & Frequency & $\begin{array}{c}\text { MI } \\
\text { Value }\end{array}$ & $\begin{array}{c}\text { Verb } \\
\text { collocate }\end{array}$ & Frequency & $\begin{array}{c}\text { MI } \\
\text { Value }\end{array}$ & $\begin{array}{c}\text { Verb } \\
\text { collocate }\end{array}$ & Frequency & $\begin{array}{c}\text { MI } \\
\text { Value }\end{array}$ \\
\hline 1 & suffer & 1144 & 4.86 & indicate & 4459 & 4.25 & improve & 1029 & 4.42 \\
\hline 2 & face & 811 & 3.46 & suggest & 3707 & 3.00 & affect & 959 & 4.22 \\
\hline 3 & result & 284 & 3.14 & produce & 3560 & 3.38 & predict & 871 & 5.08 \\
\hline 4 & mitigate & 80 & 5.02 & obtain & 1821 & 3,87 & determine & 724 & 3.59 \\
\hline 5 & anticipate & 73 & 3.02 & achieve & 1755 & 3.39 & influence & 685 & 4.89 \\
\hline 6 & foresee & 59 & 4.77 & yield & 1689 & 5.01 & achieve & 653 & 4.10 \\
\hline 7 & reap & 46 & 4.13 & interpret & 812 & 3.75 & associate & 629 & 4.20 \\
\hline 8 & entail & 44 & 3.66 & summarize & 365 & 4.05 & measure & 457 & 3.87 \\
\hline 9 & ensue & 30 & 4.05 & narrow & 286 & 3.74 & relate & 399 & 3.05 \\
\hline 10 & evade & 19 & 3.38 & replicate & 267 & 3.81 & result & 363 & 3.36 \\
\hline 11 & insulate & 13 & 3.40 & generalize & 246 & 5.16 & assess & 319 & 3.97 \\
\hline 12 & befall & 10 & 3.65 & skew & 175 & 4.58 & examine & 293 & 3.02 \\
\hline 13 & ameliorate & 10 & 4.35 & certify & 142 & 3.37 & evaluate & 254 & 3.82 \\
\hline 14 & portend & 6 & 3.92 & bias & 102 & 4.10 & yield & 146 & 3.61 \\
\hline 15 & forbear & 3 & 4.87 & corroborate & 70 & 3.30 & alter & 118 & 3.17 \\
\hline 16 & & & & tabulate & 64 & 5.04 & correlate & 106 & 4.24 \\
\hline 17 & & & & confound & 63 & 3.17 & await & 103 & 3.57 \\
\hline 18 & & & & & & & anticipate & 86 & 3.09 \\
\hline 19 & & & & & & & dictate & 68 & 3.48 \\
\hline 20 & & & & & & & attain & 39 & 3.00 \\
\hline
\end{tabular}

TABLE 5. Placement of verbs collocates of consequence, result, and outcome in COCA

\begin{tabular}{|c|c|c|}
\hline consequence & verb + consequence & $\begin{array}{l}\text { suffer, face, mitigate, anticipate, foresee, reap, evade, insulate, } \\
\text { ameliorate }\end{array}$ \\
\hline & consequence + verb & $\begin{array}{l}\text { result, entail, ensue, befall, portend, forbear } \\
\text { achieve bias certify confound corroborate generalize interpret }\end{array}$ \\
\hline result & verb + result & $\begin{array}{l}\text { narrow, obtain, produce, replicate, skew, summarize, tabulate, } \\
\text { yield }\end{array}$ \\
\hline & result + verb & indicate, suggest \\
\hline outcome & verb + outcome & $\begin{array}{l}\text { achieve, affect, alter, anticipate, assess, associate, attain, await, } \\
\text { correlate, determine, dictate, evaluate, examine, improve, } \\
\text { influence, predict, relate, result (in), yield }\end{array}$ \\
\hline
\end{tabular}


It can be seen from Table 5 that the nouns consequence, result, and outcome do not have the same distribution pattern of collocation. In terms of placement, the corpus data show that the noun consequence frequently follows the verbs suffer, face, mitigate, anticipate, foresee, reap, evade, insulate, and ameliorate, as exemplified in (3), and the verb collocates that follow consequence are result, entail, ensue, befall, portend, and forbear, as in (4).

(3) Though on different sides in this protest, both suffer the consequence of economic decline.

(4) The Prepper Movement fights everyday to preserve, protect \&; sustain a way of life they believe in no matter what consequences befall them.

The noun result also has two distribution patterns. While most of its verb collocates appear before the noun result, i.e. achieve, bias, certify, confound, corroborate, generalize, interpret, narrow, obtain, produce, replicate, skew, summarize, tabulate, and yield, as exemplified in (5), two verbs, i.e. indicate and suggest, follow it, as in (6).

(5) These were worked over the dry surface several times until I achieved the result I wanted.

(6) For ratings of both mother and father, the twin results suggested a significant and substantial genetic influence on acceptance-rejection.

As for outcome, its verb collocates, i.e. achieve, affect, alter, anticipate, assess, associate, attain, await, correlate, determine, dictate, evaluate, examine, improve, influence, predict, relate, result (in), and yield are placed before it, as exemplified in (7).

(7) Myriad officials maintain that in Europe, where U.S. patent law does not apply, competition hasn't improved outcomes.

The next step of the research procedure was analyzing semantic preference of the three target synonyms in order to group their verb collocates on the basis of their similarities in meaning. Semantic preference refers to the restriction of the co-occurrences of lexical items to those sharing a semantic feature (Sinclair, 2004). It is common for words to be limited to identifiable semantic fields (Cheng, 2012; Ang et al. 2017). In other words, semantic preference can be determined by the semantic relations between words and their collocates. Information from a collocational list helps identify the range of associations of the search word as well as the semantic relations among its collocates (Ly and Jung, 2015).

TABLE 6. Semantic preference of verb collocates of consequence

\begin{tabular}{ll}
\hline 1. HAVE & face, reap, suffer \\
2. SOLVE & ameliorate, mitigate \\
3. PREDICT & anticipate, foresee, portend \\
4. AVOID & evade, forbear, insulate \\
5. HAPPEN & befall, ensue, entail, result \\
\hline
\end{tabular}

Obviously a number of verb collocates discovered demonstrate the negative sense this particular noun conveys. Some prominent verb collocates signifying negative or adversative meaning of consequence are face, suffer, mitigate, evade, forbear, insulate, befall, and ensue, as can be seen in the contexts where these verbs appear, exemplified in (8). Looking at the words surrounding the verb collocates and consequence enables us to see the negative environments in which the collocations occur. 
(8) I actually prefer her plan as it tells the insurance companies and the market to put up or face a consequence you don't want.

Five themes stemmed from the analysis of semantic preference of the noun consequence, as shown in Table 6. The first theme HAVE includes the verbs describing the way people encounter something negative, namely face, reap, and suffer. Although the verb reap is often used with positive nouns, e.g. benefit, the combination reap consequences is also common. The second theme SOLVE is related to how a problem is remedied or rectified, with ameliorate and mitigate being its members. PREDICT, the third theme, encompasses verbs that show the way a consequence is forecast, i.e. anticipate, foresee, and portend. The next theme AVOID has to do with the verbs meaning 'to safeguard or protect someone or something from something unpleasant happening', namely evade, forbear, and insulate. The last theme is HAPPEN, containing the verbs befall, ensue, entail, and result, which often refer to the occurrence of undesirable things or situations, as exemplified in (9).

(9) When a woman succumbs to her hidden feelings for her boss without setting the other man she is seeing free, devastating consequences ensue.

TABLE 7. Semantic preference of verb collocates of result

\begin{tabular}{ll}
\hline 1. MAKE & produce, yield \\
2. GET & achieve, obtain \\
3. DO SOMETHING WITH & generalize, interpret, replicate, summarize, tabulate \\
4. AFFECT & bias, confound, narrow, skew \\
5. SUPPORT & certify, corroborate \\
6. SHOW & indicate, suggest \\
\hline
\end{tabular}

While the noun consequence is associated with verb collocates of a negative sense, result is not. A corpus-informed observation from COCA indicates that the verb collocates of result are largely 'research-oriented'. Many collocates are clearly restricted to the context of research writing, e.g. generalize, replicate, skew, corroborate. With close scrutiny, the semantic preference of result has been revealed in Table 7, which consists of six themes. In the first two themes, i.e. MAKE and GET, the verb collocates are close in meaning, in particular, produce and yield, and achieve and obtain. The third theme DO SOMETHING WITH contains the highest number of collocates, i.e. generalize, interpret, replicate, summarize, and tabulate, all of which are related to researchers' action, as exemplified in (10). The fourth theme AFFECT deals with the way research results can be affected or influenced, comprising the verb collocates bias, confound, narrow, and skew. The verb collocates in the fifth theme SUPPORT, i.e. certify and corroborate, are used in writing research papers to show that results are consistent with those of other studies, while the collocates assigned to the sixth theme SHOW, i.e. indicate and suggest, are usually used in reporting results.

(10) By being inclusive, this study avoided the problem of nonrepresentative sampling that typically is encountered when focus group results are generalized.

TABLE 8 Semantic preference of verb collocates of outcome

1. MAKE
2. GET
3. DO SOMETHING WITH
4. AFFECT
5. LINK
6. PREDICT

determine, dictate, result (in), yield

achieve, attain

assess, await, evaluate, examine, measure

affect, alter, improve, influence

associate, correlate, relate

anticipate, predict 
Upon investigation of the semantic preference of outcome through its verb collocates, six main themes were determined. Four themes of outcome and result, namely MAKE, GET, DO SOMETHING WITH, and AFFECT, overlap, and outcome shares one theme with consequence, which is PREDICT. In the first theme, MAKE, the verb result (in) and yield are close in meaning, as exemplified in (11). Meanwhile, determine and dictate are also similar in meaning, as exemplified in (12). The second theme GET has two members, namely achieve and attain. All the verb collocates under the third theme DO SOMETHING WITH, assess, evaluate, and measure, are very similar in meaning. The verb collocates in the next theme AFFECT are associated with how an outcome can be changed in a positive manner (i.e. improve) or in a neutral way (i.e. affect, alter, and influence). Regarding the fifth theme LINK, the collocates found in the corpus data show a connection or relationship between things, i.e. associate, correlate, and relate. Finally, anticipate and predict are viewed as members under the theme PREDICT because they are concerned with stating an outcome that may happen in the future.

(11) Ultimately, it was Szczerbiak's tiebreaking three with 18.1 seconds left that determined the outcome.

(12) The segment -ONIA, after loss of hiatus, i.e. -onja, could have developed in one of the following three ways, none of which, alone, could have yielded the outcome.

Having analysed the common verb collocates of consequence, result, and outcome based on the corpus data from COCA, the researcher continued to search for adjectives frequently co-occurring with the target synonyms.

ADJECTIVE COLLOCATES

TABLE 9. Adjectives collocates of consequence, result, and outcome in COCA

\begin{tabular}{|c|c|c|c|c|c|c|c|c|c|}
\hline \multirow[t]{2}{*}{ Rank } & \multicolumn{3}{|c|}{ consequence } & \multicolumn{3}{|c|}{ result } & \multicolumn{3}{|c|}{ outcome } \\
\hline & $\begin{array}{l}\text { Adjective } \\
\text { collocate }\end{array}$ & Frequency & $\begin{array}{c}\text { MI } \\
\text { Value }\end{array}$ & $\begin{array}{l}\text { Adjective } \\
\text { collocate }\end{array}$ & $\begin{array}{c}\text { Frequen } \\
\text { cy }\end{array}$ & $\begin{array}{c}\text { MI } \\
\text { Value }\end{array}$ & $\begin{array}{l}\text { Adjective } \\
\text { collocate }\end{array}$ & $\begin{array}{c}\text { Frequenc } \\
\mathbf{y} \\
\end{array}$ & $\begin{array}{c}\text { MI } \\
\text { Value }\end{array}$ \\
\hline 1 & unintended & 1944 & 10.13 & similar & 2425 & 3.08 & positive & 1670 & 5.07 \\
\hline 2 & negative & 1681 & 5.79 & positive & 2347 & 3.42 & possible & 1043 & 3.13 \\
\hline 3 & serious & 1226 & 4.32 & direct & 1592 & 3.59 & negative & 736 & 4.43 \\
\hline 4 & economic & 805 & 3.36 & previous & 1436 & 3.02 & clinical & 674 & 5.34 \\
\hline 5 & long-term & 638 & 5.00 & consistent & 1362 & 3.98 & likely & 670 & 3.15 \\
\hline 6 & dire & 634 & 7.69 & preliminary & 741 & 4.76 & educational & 577 & 4.54 \\
\hline 7 & potential & 568 & 4.02 & mixed & 691 & 4.54 & desired & 563 & 7.24 \\
\hline 8 & environmental & 406 & 3.47 & net & 657 & 3.87 & academic & 549 & 4.25 \\
\hline 9 & severe & 404 & 4.70 & experimental & 562 & 3.64 & final & 513 & 3.20 \\
\hline 10 & adverse & 393 & 6.70 & desired & 520 & 4.99 & successful & 440 & 3.44 \\
\hline 11 & devastating & 363 & 6.06 & surprising & 512 & 3.15 & adverse & 431 & 6.69 \\
\hline 12 & disastrous & 357 & 7.01 & statistical & 432 & 3.48 & primary & 427 & 3.84 \\
\hline 13 & direct & 335 & 3.62 & promising & 419 & 3.59 & long-term & 347 & 3.98 \\
\hline 14 & inevitable & 281 & 5.11 & disastrous & 381 & 4.78 & improved & 344 & 5.59 \\
\hline 15 & tragic & 226 & 5.04 & inevitable & 334 & 3.05 & potential & 332 & 3.10 \\
\hline 16 & far-reaching & 208 & 7.58 & encouraging & 285 & 3.28 & behavioral & 266 & 5.04 \\
\hline 17 & immediate & 207 & 3.71 & predictable & 281 & 3.73 & favorable & 250 & 5.64 \\
\hline 18 & logical & 204 & 4.76 & empirical & 275 & 3.42 & expected & 233 & 4.96 \\
\hline 19 & grave & 193 & 5.73 & disappointing & 272 & 3.95 & ultimate & 201 & 3.77 \\
\hline 20 & catastrophic & 187 & 5.97 & descriptive & 261 & 4.18 & inevitable & 187 & 4.34 \\
\hline 21 & practical & 186 & 3.61 & tangible & 249 & 4.18 & secondary & 174 & 4.05 \\
\hline 22 & profound & 175 & 4.60 & inconsistent & 223 & 3.86 & desirable & 164 & 5.17 \\
\hline 23 & unfortunate & 164 & 4.67 & conflicting & 217 & 3.96 & functional & 159 & 424 \\
\hline 24 & psychological & 161 & 3.60 & comparable & 214 & 3.05 & developmental & 143 & 4.53 \\
\hline 25 & enormous & 149 & 3.33 & quantitative & 199 & 3.66 & uncertain & 132 & 4.44 \\
\hline 26 & deadly & 147 & 3.98 & favorable & 193 & 3.13 & distal & 126 & 7.41 \\
\hline
\end{tabular}




\begin{tabular}{lccccccccc}
\hline $\mathbf{2 7}$ & unforeseen & 144 & 7.62 & qualitative & 167 & 3.32 & psychological & 122 & 3.05 \\
$\mathbf{2 8}$ & harmful & 137 & 4.96 & inconclusive & 160 & 5.30 & predictable & 112 & 4.54 \\
$\mathbf{2 9}$ & ecological & 123 & 4.59 & catastrophic & 157 & 3.43 & beneficial & 109 & 4.15 \\
$\mathbf{3 0}$ & fatal & 120 & 4.45 & satisfactory & 150 & 4,02 & cognitive & 108 & 3.30 \\
\hline
\end{tabular}

The corpus-based information from Table 9 confirms synonymy among the three target words because consequence, result, and outcome share certain common collocates. Inevitable is the only adjective collocate modifying all the three synonyms found in the selected COCA data. The adjective collocates that consequence and result share are disastrous and catastrophic. Those typically co-occurring with consequence and outcome are negative, adverse, long-term, potential, and psychological. Finally, result and outcome were found to have two adjective collocates in common, namely positive and predictable. It is also important to note that the shared adjective collocates are limited to those presented in Table 9.

There are possibly more collocates which the three synonyms can actually share. Their absence from Table 8, however, may result from the adjective-collocate selection criteria that exclude either those with an MI score that is lower than 3 or those that do not appear in the top30 list. For example, the adjective predictable can be combined with all the target synonyms but it is not in the collocation list of consequence because of its relatively low frequency, in comparison to those in the top-30 list.

TABLE 10. Semantic preference of adjective collocates of consequence

\begin{tabular}{ll}
\hline 1. NEGATIVE SENSE & adverse, catastrophic, deadly, devastating, dire, disastrous, fatal, grave, harmful, negative, \\
& serious,severe, tragic, unfortunate \\
2. TYPE & ecological, economic, environmental, logical, practical, psychological \\
3. TIME & immediate, long-term \\
4. POSSIBILITY & inevitable, potential \\
5. EXTENT & enormous, far-reaching, profound \\
6. MISCELLANEOUS & direct, unforeseen, unintended \\
\hline
\end{tabular}

All the adjective collocates were then classified, according to their semantic preference. In Table 10, the adjective collocates of consequence were categorised into six themes, namely NEGATIVE SENSE, TYPE, TIME, POSSIBILITY, EXTENT, and MISCELLANEOUS. The majority of its adjective collocates, represented by NEGATIVE SENSE, are strongly associated with negative or adversative contexts, which is in line with the findings of several verb collocates accompanying consequence, as reflected in Table 6 . Their core meanings are associated with 'causing damage, destruction, failure, or death', as demonstrated by the adjectives adverse, catastrophic, deadly, devastating, dire, disastrous, fatal, grave, harmful, negative, serious, severe, tragic, and unfortunate, as exemplified in (13). The second theme TYPE includes adjectives referring to a variety of topics like ecological, economic, environmental, logical, practical, and psychological. It is worth mentioning here that the meaning of practical in this particular context does not have anything to do with 'likely to succeed or be effective' but 'relating to real situations and events'.

(13) In general, the greater the magnitude of any claimed catastrophic consequence of global warming, the smaller the likelihood of it occurring.

As for the next theme TIME, adjectives indicating temporal ideas are included, i.e. immediate and long-term, as in (14), while in POSSIBIITY, 'the possibility of something happening or being developed' is denoted by inevitable and potential, the former of which implies a negative or unpleasant result. The fifth theme EXTENT relates to how large, serious, or important a consequence is, consisting of three collocates, enormous, far-reaching, and 
profound, all of which principally show a strong influence or effect. Three final adjectives are grouped together in MISCELLANEOUS, namely direct, unforeseen, and unintended.

(14) Index futures contracts are promises to make payments, so the Fed's trades would have no immediate consequence for the quantity of money.

TABLE 11. Semantic preference of adjective collocates of result

\begin{tabular}{ll}
\hline 1. RESEARCH-ORIENTED & $\begin{array}{l}\text { comparable, consistent, conflicting, descriptive, empirical, experimental, mixed, } \\
\text { predictable, preliminary, previous, qualitative, quantitative, inconclusive, } \\
\text { inconsistent, } \\
\text { statistical, surprising }\end{array}$ \\
2. NEGATIVE SENSE & $\begin{array}{l}\text { catastrophic, disappointing, disastrous } \\
\text { desired, encouraging, favorable, positive, promising, satisfactory, tangible }\end{array}$ \\
3. POSITIVE SENSE & inevitable \\
4. POSSIBILITY & net \\
\hline
\end{tabular}

Through a closer investigation into the semantic preference of adjective collocates of results, five major themes emerged. The majority of the discovered adjectives fall into the first theme RESEARCH-ORIENTED, which is consistent with the findings of verb collocates of result prevalent in research-based genres previously discussed. The adjectives which prevail in the research-related contexts are comparable, consistent, conflicting, descriptive, empirical, experimental, mixed, predictable, preliminary, previous, qualitative, quantitative, inconclusive, inconsistent, statistical, and surprising, as exemplified in (15). Lower in variety than those modifying consequence, three adjective collocates of result under NEGATIVE SENSE are catastrophic, disappointing, and disastrous, as shown in (16) However, one key difference between the adjective collocates co-occurring with consequence and result is that while a number of consequence collocates express a negative sense, there exist certain collocates of result that are positive in meaning, i.e. desired, encouraging, favorable, positive, promising, satisfactory, and tangible. One adjective collocate indicating possibility is inevitable, and the last one, net, which does not belong to any theme, is placed under MISCELLANEOUS. It should be noted that net result is a fixed phrase meaning 'the situation that exists at the end of a series of events'.

(15) This second research philosophy begins from some observational or experimental result and attempts to integrate the finding within some theoretical context.

(16) And reducing the economic help needed to bolster these nations that undertake to help defend freedom can have the same disastrous result.

TABLE 12. Semantic preference of adjective collocates of outcome

\begin{tabular}{ll}
\hline 1. TYPE & academic, behavioral, clinical, cognitive, developmental, educational, functional, \\
& psychological \\
2. POSITIVE SENSE & beneficial, desirable, desired, expected, favorable, improved, positive, successful \\
3. POSSIBILITY & inevitable, likely, possible, potential \\
4. SEQUENCE/PRIORITY & final, primary, secondary, ultimate \\
5. NEGATIVE SENSE & adverse, negative, uncertain \\
6. TIME & long-term \\
7. LOCATION & distal \\
8. MISCELLANEOUS & predictable \\
\hline
\end{tabular}

The adjective collocates of outcome are connected with more themes than consequence and result. Of all the eight themes shown in Table 12, most of the co-occurring adjectives are concerned with different types or topics (TYPE), i.e. academic, behavioral, clinical, cognitive, 
developmental, educational, functional, and psychological, as exemplified in (17). Like those of result, adjective collocates of outcome express POSITIVE SENSE, i.e. beneficial, desirable, desired, expected, favorable, improved, positive, and successful, as well as POSSIBILITY, i.e. inevitable, likely, possible, and potential. There are also some adjectives representing SEQUENCE/PRIORITY, as in final, primary, secondary, and ultimate. Similar to consequence and result, outcome also collocates with adjectives that express NEGATIVE SENSE, i.e. adverse, negative, and uncertain. The three remainders of the adjective collocates has been assigned to TIME (i.e. long-term), LOCATION (i.e. distal), and MISCELLANEOUS (i.e. predictable), respectively.

(17) As was the case for the other meta-analyses, the mean effect size for academic outcome was in the small range ( $\mathrm{M}$ within-group $\mathrm{ES}=0.19$ ).

In summary, many adjectives that frequently collocate with the three target nouns consequence, result, and outcome share some common themes, namely NEGATIVE SENSE, TIME, and POSSIBILITY, which may be indicative of synonymy among all the three words. In-depth analysis revealed subtle differences in semantic preference with which the synonyms are associated. While the typical adjectives describing consequence are representative of negative senses, a number of adjective collocates accompanying result are used in researchrelated contexts. In addition, outcome has adjective collocates with the highest variance of themes.

The findings of this study are in line with previous research in many respects. In terms of genres, the three synonyms consequence, result, and outcome are prevalent in academic texts, which substantiates their high level of formality. This provides additional evidence that some synonymous words differ in the degree of formality, as shown in previous studies (e.g. Phoocharoensil, 2010; Jirananthiporn, 2018). In addition, it was discovered that the three nouns sometimes share verb and adjective collocates. This confirms their statuses as synonyms of one another. Different collocations specific to each noun systematically distinguish all the synonyms. By way of illustration, some particular adjectives or verbs are likely to co-occur with one synonym rather than another, which lends support to a number of studies (e.g. Aroonmanakun, 2015; Chung, 2011; Crawford and Csomay, 2016; Jirananthiporn, 2018; Petcharat and Phoocharoensil, 2017).

\section{CONCLUSION}

This corpus-based study explored the similarities and differences between three synonyms, namely consequence, result, and outcome, with emphasis on their distribution across eight genres in COCA and their frequently-occurring verb and adjective collocates. The results have clearly revealed that all the target synonyms are used with the highest frequency in academic texts, which suggests that they are all associated with a high degree of formality. More precisely, consequence and outcome are lowest in frequency in TV and movie subtitles, and result in fiction. The prevailing language in these two genres is characteristic of informal English.

In addition to the distribution patterns exhibited from the corpus data, this study also presents the top- 20 verbs and the top-30 adjectives which most strongly collocate with these synonyms. According to COCA, outcome has more typical verb collocates than result and consequence respectively.

A comprehensive analysis of semantic preference of verb/adjective collocation unveils subtle usage differences among the synonyms. It is shown that consequence is by and large 
closely related to words with negative sense. Despite being a near-synonym of consequence, result does not have a clear association with negative or adversative contexts. Instead, the collocates of results are more common in research methodology. Unlike consequence and result, outcome combines with collocates with a wide variety of semantic properties. One of the most common themes concerns topics or types, as indicated by adjectives like psychological.

The current study, however, has certain limitations. The number of verb and adjective collocates are limited to those in the top-20 and top-30 lists, respectively. An inclusion of collocates with comparatively lower frequency will provide a clearer picture of collocational patterns of the target synonyms. Furthermore, statistical tests in addition to MI can also be taken into account. Alternatively, a combined application of MI scores and T-scores, which focus on the number of joint frequencies (Cheng, 2012), can be used in collocation analysis. Another limitation lies in the linguistic traits of synonyms being investigated. While this study mainly looked at distribution and collocation patterns, other aspects, such as grammatical patterns, can also be considered. Furthermore, since only three synonyms are the focus of this study, a further study may also include other synonyms in the same group, e.g. effect or impact, or examine other sets of synonyms. Additionally, although the present-study analysis is based on COCA, the findings may not be generalised to include other major varieties of English, namely British English. It is recommended that future researchers examine synonym usage in other Englishes or conduct a comparative synonym study across Englishes.

\section{REFERENCES}

Ang, L. H., Tan, K. H., \& He, M. Y. (2017). A Corpus-based Collocational Analysis of Noun Premodification Types in Academic Writing. 3L The Southeast Asian Journal of English Language Studies, 23(1), 115135. doi: 10.17576/31-2017-2301-09

Aroonmanakun, V. (2015). 'Quick' or 'fast': A corpus-based study of English synonyms. LEARN Journal: Language Education and Acquisition Research Network. 8(1), 53-62.

Barnbrook, G, Mason, O. \& Krishnamurthy, R. (2013). Collocation. Applications and implications. London: Palgrave Macmillan.

Cheng, W. (2012). Exploring corpus linguistics. Language in action. London: Routledge.

Chung, S-F. (2011). A corpus analysis of 'create' and 'produce'. Chang Gung Journal of Humanities and Social Sciences. 4(2), 399-425

Coxhead, A. (2000). A new academic word list. TESOL Quarterly. 34(2), 213-238.

Crawford, W. J. \& Csomay, E. (2016). Doing corpus linguistics. London: Routledge.

Cruse, D. A. (1986). Lexical semantics. Cambridge: Cambridge University Press.

Davies, M. (2020, June 25). The new corpus of contemporary American English (COCA 2020). Language Institute Thammasat University (LITU) Webinar, Bangkok, Thailand. https://www.youtube.com/watch?v=zW9I9C9rPD4

Flowerdew, L. (2012). Corpora and language education. London: Palgrave Macmillan.

Hill, J. (2000). Revisiting priorities: From grammatical failure to collocational success. In M. Lewis (Ed.). Teaching collocation: Further development in the lexical approach (pp. 47-69). London: Commercial Colour Press Plc.

Jackson, H. \& Amvela, E. (2007). Words, meaning, and vocabulary: An introduction to modern English lexicology. London: Cassel.

Jirananthiporn, S. (2018). Is this problem giving you trouble? A corpus-based examination of the differences between the nouns 'problem' and 'trouble'. Thoughts 2018. 2, 1-25.

Lee, C. \& Liu, J. (2009). Effects of collocation information on learning lexical semantics for near Synonym distinction. Computational Linguistics and Chinese Language Processing. 14(2), 205-220

Louw, B. (1993). Irony in the text or insincerity in the writer? In M. Baker et al. (Eds). Text and technology. Amsterdam: John Benjamins.

Longman advanced American dictionary. (2013). Essex: Pearson Education.

Ly, T. H. \& Jung, C. K. (2015). A corpus investigation: The similarities and differences of 'cute', 'pretty' and 'beautiful'. 3L: The Southeast Asian Journal of English Language Studies. 21(3), 125-140. http://ejournals.ukm.my/31/article/view/8788/3426

Merriam-Webster dictionary. https://www.merriam-webster.com/ 
Oxford

advanced

American

dictionary.

https://www.oxfordlearnersdictionaries.com/definition/american_english/

Petcharat, N. \& Phoocharoensil, S. (2017). A corpus-based study of English synonyms:'appropriate', 'proper', and 'suitable'. LEARN Journal: Language Education and Acquisition Research Network. 10(2), 90-99.

Phoocharoensil, S. (2010). A corpus-based study of English synonyms. International Journal of Arts and Sciences. 3(10), 227-245.

Schmitt, N. (2010). Researching vocabulary. A vocabulary research manual. London: Palgrave Macmillan.

Sinclair, J. (2004). Trust the text. London: Routledge.

Sridhanyarat, K. (2018). Thai learners' acquisition of L2 collocations: An interlanguage perspective. GEMA Online Journal of Language Studies, 18(1), 1-21.

Stubbs, M. (1995). Collocations and semantic profiles: On the cause of trouble with quantitative studies. Functions and language. 2(1), 23-55.

Szudarski, P. (2018). Corpus linguistics for vocabulary: A guide for research. London: Routledge.

Taylor, J. (2002). Near synonyms as co-extensive categories: 'high' and 'tall' revisited. Language Sciences. 25(3), 263-284.

Thornbury, S. (2002). How to teach vocabulary. Harlow: Longman.

Webb, S. \& Nation, P. (2017). How vocabulary is learned. Oxford: Oxford University Press.

Wongkhan, P. \& Thienthong, A. (2020). EFL learners' acquisition of academic collocation and synonymy: Does their academic experience matter? RELC Journal. March 2020, 1-16. 